\title{
One-step heating strategy for efficient solubilization of recombinant spider silk protein from inclusion bodies
}

\author{
Hui Cai ${ }^{1+}$, Gefei Chen ${ }^{2 \dagger}$, Hairui Yu ${ }^{1}$, Ying Tang ${ }^{1}$, Sidong Xiong ${ }^{1 *}$ and Xingmei $\mathrm{Qi}^{1^{*}}(\mathbb{D}$
}

\begin{abstract}
Background: Spider silk is a proteinaceous fiber with remarkable mechanical properties spun from spider silk proteins (spidroins). Engineering spidroins have been successfully produced in a variety of heterologous hosts and the most widely used expression system is Escherichia coli (E. coli). So far, recombinantly expressed spidroins often form insoluble inclusion bodies (IBs), which will often be dissolved under extremely harsh conditions in a traditional manner, e.g. either $8 \mathrm{~mol} / \mathrm{L}$ urea or $6 \mathrm{~mol} / \mathrm{L}$ guanidine hydrochloride, highly risking to poor recovery of bioactive proteins as well as unexpected precipitations during dialysis process.

Results: Here, we present a mild solubilization strategy —one-step heating method to solubilize spidroins from IBs, with combining spidroins' high thermal stability with low concentration of urea. A 430-aa recombinant protein (designated as NM) derived from the minor ampullate spidroin of Araneus ventricosus was expressed in E. coli, and the recombinant proteins were mainly present in insoluble fraction as IBs. The isolated IBs were solubilized parallelly by both traditional urea-denatured method and one-step heating method, respectively. The solubilization efficiency of NM IBs in Tris- $\mathrm{HCl}$ pH 8.0 containing $4 \mathrm{~mol} / \mathrm{L}$ urea by one-step heating method was already comparable to that of $7 \mathrm{~mol} / \mathrm{L}$ urea with using traditional urea-denatured method. The effects of buffer, $\mathrm{pH}$ and temperature conditions on NM IBs solubilization of one-step heating method were evaluated, respectively, based on which the recommended conditions are: heating temperature $70-90^{\circ} \mathrm{C}$ for $20 \mathrm{~min}, \mathrm{pH} 7.0-10$, urea concentration 2-4 mol/L in normal biological buffers. The recombinant NM generated via the one-step heating method held the potential functions with self-assembling into sphere nanoparticles with smooth morphology.

Conclusions: The one-step heating method introduced here efficiently solubilizes IBs under relatively mild conditions compared to the traditional ones, which might be important for the downstream applications; however, this protocol should be pursued carefully in terms of urea-induced modification sensitive applications. Further, this method can be applied under broad buffer, $\mathrm{pH}$ and temperature conditions, conferring the potential to apply to other thermal stable proteins.
\end{abstract}

Keywords: Heating, Recombinant spidroin, Inclusion body solubilization, NM IBS

\footnotetext{
* Correspondence: sdxiongfd@126.com; xmqi@suda.edu.cn

${ }^{+}$Hui Cai and Gefei Chen contributed equally to this work.

${ }^{1}$ The Jiangsu Key Laboratory of Infection and Immunity, Institutes of Biology and Medical Sciences, Soochow University, Suzhou 215123, Jiangsu, China Full list of author information is available at the end of the article
}

(c) The Author(s). 2020 Open Access This article is licensed under a Creative Commons Attribution 4.0 International License, which permits use, sharing, adaptation, distribution and reproduction in any medium or format, as long as you give appropriate credit to the original author(s) and the source, provide a link to the Creative Commons licence, and indicate if changes were made. The images or other third party material in this article are included in the article's Creative Commons licence, unless indicated otherwise in a credit line to the material. If material is not included in the article's Creative Commons licence and your intended use is not permitted by statutory regulation or exceeds the permitted use, you will need to obtain permission directly from the copyright holder. To view a copy of this licence, visit http://creativecommons.org/licenses/by/4.0/ The Creative Commons Public Domain Dedication waiver (http://creativecommons.org/publicdomain/zero/1.0/) applies to the data made available in this article, unless otherwise stated in a credit line to the data. 


\section{Background}

Spider silk is a kind of ideal biomaterial attributed to its extraordinary performances, such as outstanding mechanical properties and excellent biocompatibility [1-3]. In nature silk proteins are specifically spun into fibers, whereas after processed under various condition in vitro they can assemble into different forms with distinct morphologies, e.g. films, hydrogels, fibers, capsules and particles [2, 4]. The versatility of silk proteins along with their biochemical properties make silk-derived materials potentially suitable for tissue engineering and regeneration as well as controllable delivery of protein drugs and peptide vaccines [5-9]. Due to difficulties in breeding spiders and collecting silks, native spider silk is not economic and realistic to harvest on a large scale, while in nowadays recombinant production is becoming the main strategy for obtaining either spider silk protein (spidroin) or artificial spider fiber [10-13]. Orb-weaving spiders can have up to seven different silk glands for manufacturing different types of silk with specific biological function and unique mechanical properties [14]. Most recent studies have focused on the dragline silk, which is displayed with high tensile strength. The recombinant truncated dragline silk protein (major ampullate spidroin, MaSp) was shown to form nanoparticles with possibilities as drug delivery vehicles and peptide vaccines delivery system $[4,8,9]$. However, alternative biomaterials with different properties may be needed for different applications. The minor ampullate silk, distinctive from dragline silk, is used for prey wrapping and webstabilizing auxiliary spirals [15]. Interestingly, this silk shares similar tensile strength as dragline silk but with low elasticity, and does not supercontract when hydrated [16]. Hence, minor ampullate silk could be interesting for particular biomedical applications.

Spider silk is built up of large spidroins consisting of three parts, a non-repetitive N-terminal (NT) domain, a predominant highly repetitive central domain, and a nonrepetitive C-terminal (CT) domain [15, 17, 18]. For heterologous expression, the repetitive gene sequence coding for the repetitive central domain usually causes problems such as premature termination in protein synthesis, low yield and poor solubility. Several strategies have been tried to overcome these problems, including codon optimization, growing in enriched media and use of different gene constructs [19-21]. Additionally, a variety of heterologous expression hosts have also been attempted to produce recombinant spidroins, e.g. bacteria, yeast, plants, mammalian cells, and transgenic animals, each with its own pros and cons in terms of cost, manipulation, expression levels and contaminations [22-24]. The most widely used expression system is Escherichia coli $(E$. coli) owing to the most efficient, simple manipulation and cost-efficient production suitable for large-scale production [20, 22, 25].
To prepare pure recombinant spidroins, different strategies, e.g. affinity chromatography [26], thermal extraction [27, 28] and acidic extraction [27-29] have been pursued. Affinity chromatography is the most often used approach for recombinant spidroin purification, though an affinity tag is required. As the affinity tag might alter the protein properties, an additional step is normally necessary to cleave it out. Thermal and acidic extraction methods are based on spidroins' innate properties-thermal stability and solubility characteristics, during which the majority of the host proteins are precipitated at high temperature and concentrated acid, while silk proteins remain soluble. These methods circumvent the need of an affinity tag, which is favorable for biomedical applications. Unfortunately, the pure protein from the thermal extraction method is usually largely diluted and an ammonium sulfated mediated concentration step is needed, which often induces precipitation $[27,28]$. To obtain soluble proteins, the precipitated proteins are dissolved in guanidine and dialyzed against non-denaturing buffer. Proteins extracted in presence of organic acids normally have to pass an affinity or ion exchange column, which is a longlasting time and high cost process [29]. Besides, expression of recombinant spidroins has often resulted in insoluble IB formation [24, 30], however, in some cases forming of IBs is advantageous as IBs are easily isolated with high yield and purity. Traditionally, protein solubilization from IBs is often achieved under harsh conditions, i.e. using high concentration of denaturant $-8 \mathrm{~mol} / \mathrm{L}$ urea or $6 \mathrm{~mol} / \mathrm{L}$ guanidine hydrochloride. Before processing the target proteins into various formats, these harsh denaturants must be removed completely. Generally, solubilization of IBs with high concentration of denaturing reagents often leads to poor recovery of bioactive species, and large amount of precipitations form during the refolding process $[31,32]$.

In this study, to make efficient preparation of recombinant spidroins and give some insights for assembly characterization, we first expressed a 430 residues truncated spidroin (designated as NM) derived from Araneus ventricosus minor ampullate spidroin (MiSp) in E. coli. This truncated spidroin consists of the conserved nonrepetitive NT domain and one repetitive unit, while the full-length $A$. ventricosus MiSp comprises a central predominant repetitive region and the conserved nonrepetitive NT and CT domains [15]. The recombinant NM was successfully expressed in E. coli but as IBs. We then evaluated a relatively mild strategy - solubilizing NM IBs with short-term heating in the presence of low concentration of urea, referred as one-step heating method. With this method, we got highly pure and concentrated NM proteins, capable of self-assembling into sphere nanoparticles.

\section{Results}

NM architecture and recombinant expression

The detailed amino acid sequence of NM is shown in Fig. 1a, while Fig. 1b presents the architecture. The NM 
A

MSQPIWTNPNAAMTMTNNLVQCASRSGVLTADQMDDMGM MADSVNSQMQKMGPNPPQHRLRAMNTAMAAEVAEVVATSP PQSYSAVLNTIGACLRESMMQATGSVDNAFTNEVMQLVKML SADSANEVSTASASGASYATSTSSAVSSSQATGYSTAAGYG NDDDDKHMGEGAGAAAAAGAGAGGAGGYGGGAGSGAGA VARAGAGGAGGYGSGIGGGYGSGAGAAAGAGAGGAGANG GGYGTGAGAGARGADSAGAAAGYGGGVGTGTGSSAGYGR GAGAGAGAGAAAGSGAGAAGGYGGGYGAGAGAGAGAGG AGAGAGGAGGYAQGYGAGAGAGAGAGTGAGGAGGYGQG YGAGSGAGAGGAGGYGAGAGAGAGAGGASGYGQGYGDG AGAGAGAAAAAGAAAGARGAGGYGGGAGDGAGAGAGALE

B

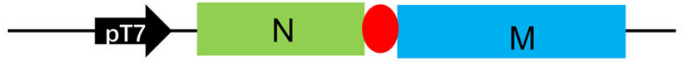

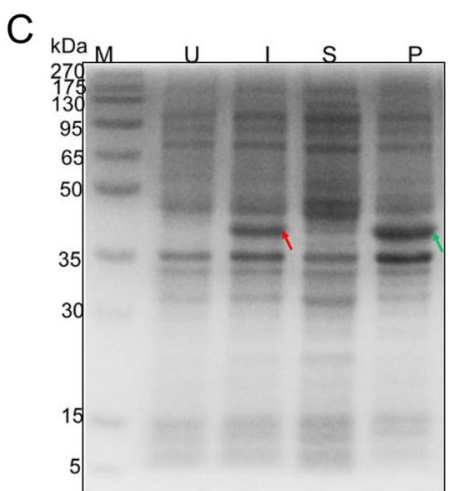

Fig. 1 Amino acid sequence, plasmid construction and NM expression. a Amino acid sequence of NM protein derived from the A. ventricosus MiSp. The NM sequence consists of the NT domain (161-aa, in green) and a truncated repetitive region (261-aa, in blue), between which there is an enterokinase cleavage site (DDDDK). b The gene fragment coding for NM was inserted into pET-32a plasmid within Ndel and Xhol restriction sites to construct expression vector pET-NM. c SDS-PAGE analysis of the recombinant protein NM expressed in E. coli BL21 (DE3) cells. Lane M for protein size markers $(\mathrm{kDa})$, lanes $U$ and I for total cellular proteins of $E$. coli before and after IPTG-induced protein expression, respectively, lanes $\mathrm{S}$ and $\mathrm{P}$ for the supernatants and pellets of the bacterial cell lysate after sonication, respectively. The theoretical molecular weight of NM is $38 \mathrm{kDa}$

recombinant expression was conducted at $37^{\circ} \mathrm{C}$ and the final IPTG concentration was $1 \mathrm{mmol} / \mathrm{L}$. Indicated by the SDS-PAGE (Fig. 1c), compared to the control sample (lane U) there is an additional strong band (red arrow) after IPTG induction (lane I), which fits very well to the target protein NM judged by its apparent size of $38 \mathrm{kDa}$. After bacterial cell disruption, the soluble (lane S) and insoluble cell fractions (lane P) were separated by centrifuge. The NM was mainly in pellet fraction as inclusion bodies (green arrow). These results indicate that recombinant spider silk protein NM can be efficient expressed as inclusion bodies (NM IBs) in E. coli.

\section{Isolation and solubilization of NM IBs}

Pure NM IBs were prepared through extensive washing with detergent containing buffer, after which majority of contaminants were removed. The NM IBs purity was evaluated by SDS-PAGE, which is up to $70 \%$ (black arrow, Fig. 2a). The purified NM IBs $(10 \mathrm{mg} / \mathrm{mL}$ wet weight concentration) were resuspended in Tris- $\mathrm{HCl}$ $\mathrm{pH} 8.0$ containing different concentrations of urea $(0-7$ $\mathrm{mol} / \mathrm{L})$, and further proceeded with one step-heating method and traditional urea-denature method. The solubilized supernatants of NM IBs from both methods were analyzed by SDS-PAGE (Fig. $2 \mathrm{~b}$ and $\mathrm{c}$ ), and the protein concentrations were measured by Micro BCA Protein Assay kit (Table 1), respectively. With traditional ureadenatured method, NM IBs were largely solubilized in Tris- $\mathrm{HCl} \mathrm{pH} 8.0$ containing $5-7 \mathrm{~mol} / \mathrm{L}$ urea, whereas with $0-4 \mathrm{~mol} / \mathrm{L}$ urea the solubilization efficiency was rather low (Fig. 2b). Interestingly, by performing the onestep heating method Tris- $\mathrm{HCl} \mathrm{pH} 8.0$ containing $0-7 \mathrm{~mol} /$ L urea all solubilized NM IBs, and at $4 \mathrm{~mol} / \mathrm{L}$ urea concentration the solubilization efficiency was already up to $80 \%$, which is around three times higher than that of traditional urea-denature method. Interestingly, Tris- $\mathrm{HCl} \mathrm{pH} 8.0$ alone could also solubilize NM IBs (Lane 0, Fig. 2c) to some extent. These results indicated that short-term heating improves the solubilization of NM IBs, and the efficiency achieved through one-step heating method in the presence of $4 \mathrm{~mol} / \mathrm{L}$ urea is comparable to that of $7 \mathrm{~mol} / \mathrm{L}$ urea via traditional urea-denatured method (Fig. 2d). Hence, for testing other potential affecting factors below, the urea concentration was stuck to $4 \mathrm{~mol} / \mathrm{L}$.

\section{Solubilization of NM IBs at different temperatures and pHs}

In order to optimize the heating temperature that is essential for solubilization of NM IBs when performing one-step heating method, we tested effects from different temperatures, ranging from 40 to $100{ }^{\circ} \mathrm{C}$, in 10 $\mathrm{mmol} / \mathrm{L}$ Tris- $\mathrm{HCl} \mathrm{pH} 8.0$ containing $4 \mathrm{~mol} / \mathrm{L}$ urea. As shown in Fig. 3, the solubilization capability was progressively increased when the heating temperature rose, and the plateau was reached at around $85^{\circ} \mathrm{C}$. Considering the thermal stability of spidroins, the heating temperature is optimized as $85^{\circ} \mathrm{C}$ for following evaluations. Similarly, to find out the most suitable working $\mathrm{pH}$ the purified NM IBs were solubilized in $10 \mathrm{mmol} / \mathrm{L}$ Tris- $\mathrm{HCl}$ at different $\mathrm{pHs}(\mathrm{pH} 5-10)$ containing $4 \mathrm{~mol} / \mathrm{L}$ urea. The suspensions were mixed thoroughly and heated at $85^{\circ} \mathrm{C}$ for $20 \mathrm{~min}$. The soluble fractions containing NM were analyzed by SDS-PAGE. The results showed the solubilization efficiency was also affected by the working $\mathrm{pH}$, with an increasing tendency from $\mathrm{pH} 5$ to 7 , while the different between $\mathrm{pH} 7,8,9$ and 10 was not very obvious (Fig. 4), suggesting NM IBs solubilization by one-step heating method can be working under broad $\mathrm{pH}$ conditions. 
A

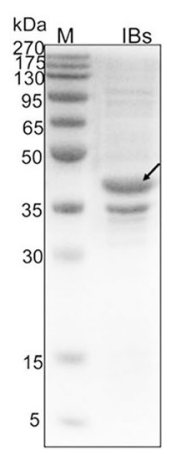

C
B

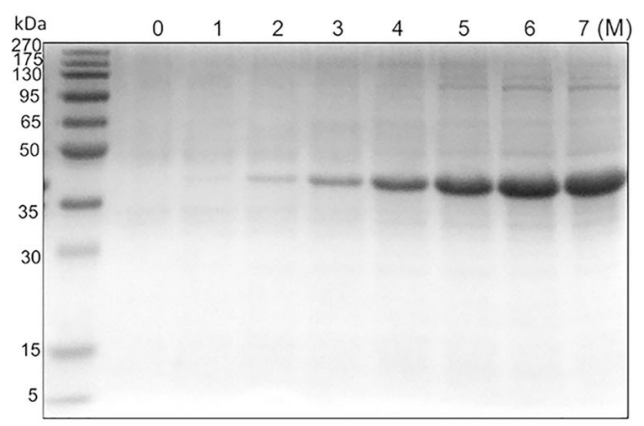

D
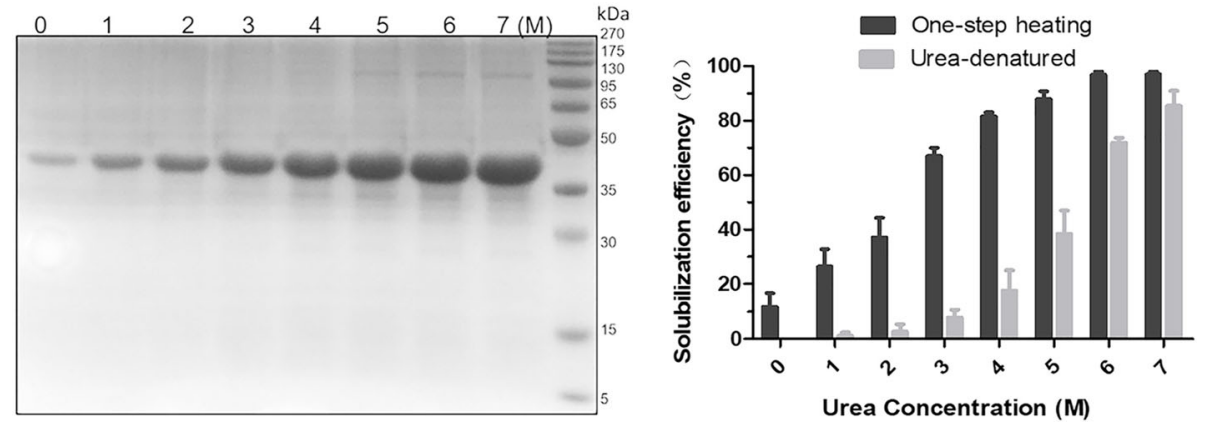

Fig. 2 NM IBs isolation and solubilization. a SDS-PAGE analysis of the purified NM IBS after extensive washing. b SDS-PAGE analysis of the solubilized NM from IBs by traditional urea-denatured method with 0-7 mol/L urea. c SDS-PAGE analysis of the solubilized NM protein from IBs by one-step heating method with $0-7 \mathrm{~mol} / \mathrm{L}$ urea. $\mathbf{d}$ The protein solubilization efficiency by two different methods with $0-7 \mathrm{~mol} / \mathrm{L}$ urea

\section{Solubilization of NM IBs in different buffers}

The solubilization of IBs might be influenced by different normally used buffer conditions. To figure this out, five different buffers were tested in this study. The results showed that the buffer conditions did not significantly affect the solubilization efficiency of NM IBs (Fig. 5a), indicated by the bands with similar intensity from $10 \mathrm{mmol} /$ $\mathrm{L} \mathrm{NaCO}_{3}(\mathrm{pH} 8.0), 10 \mathrm{mmol} / \mathrm{L} \mathrm{K}_{3} \mathrm{PO}_{4}(\mathrm{pH} 8.0), 10 \mathrm{mmol} /$ $\mathrm{L}$ Tris- $\mathrm{HCl}(\mathrm{pH} 8.0)$ and deionized water $(\mathrm{ddH} 2 \mathrm{O})$, even

Table 1 Solubilization of NM spidroins from IBs with different concentrations of urea through two different methods

\begin{tabular}{lll}
\hline $\begin{array}{l}\text { Urea } \\
\text { conc. } \\
\begin{array}{l}\text { (mol/ } \\
\text { L) }\end{array}\end{array}$ & Protein concentration $(\mathrm{ng} / \mathrm{ml})$ & \\
\cline { 2 - 3 } & One-step heating method & Traditional urea-denatured \\
\hline 0 & 483 & 0 \\
1 & 952 & 58 \\
2 & 1290 & 157 \\
3 & 1866 & 311 \\
4 & 2335 & 728 \\
5 & 2641 & 1368 \\
6 & 2786 & 2143 \\
7 & 2912 & 2458 \\
\hline
\end{tabular}

though a slight decrease in $1 \times$ PBS was observed. These results suggest the one-step heating method holds the potential to work under a wide range of biological buffers without significantly decreasing the solubilization capability.

\section{Self-assembly of NM protein into nanoparticles}

To evaluate recombinant NM generated by the one-step heating method in a function point of view, the NM nanoparticle self-assembly was induced by salting out with potassium phosphate. As a result, the recombinant NM successfully self-assembled into nanoparticles. Under scanning electron microscope, well-distributed even spherical nanoparticles with diameter around 500 $\mathrm{nm}$ were observed (Fig. 6). The NM nanoparticles shared similar morphology as previous reported nanoparticles formed by other recombinant spidroins [2, 9], and might have potential and specific applications as functional biomaterials, e.g. controllable delivery of protein drugs /peptide vaccines.

\section{Identification of urea-induced modification}

To identify potential carbamylation from urea, the recombinant NM generated with above protocol was trypsinated and analyzed by mass spectrometry. Due to 


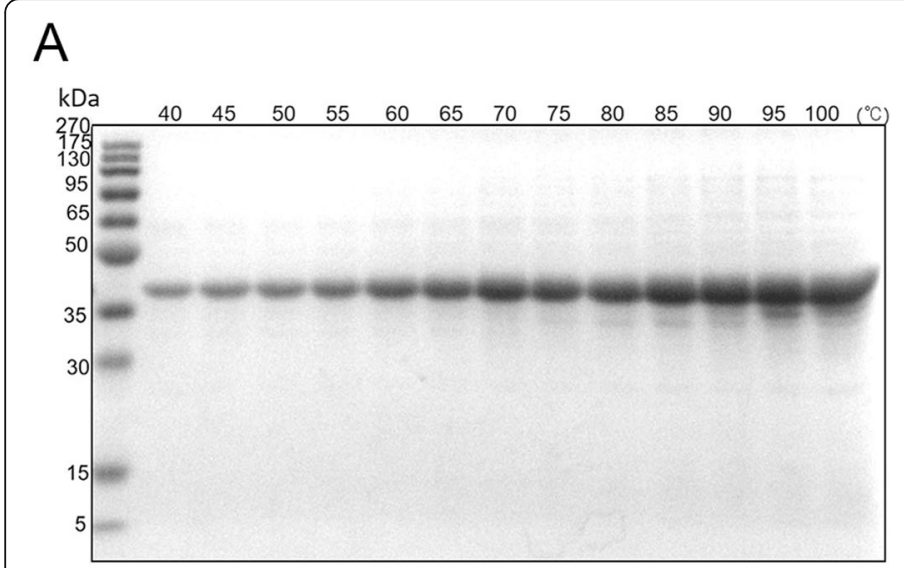

$\mathrm{B}$

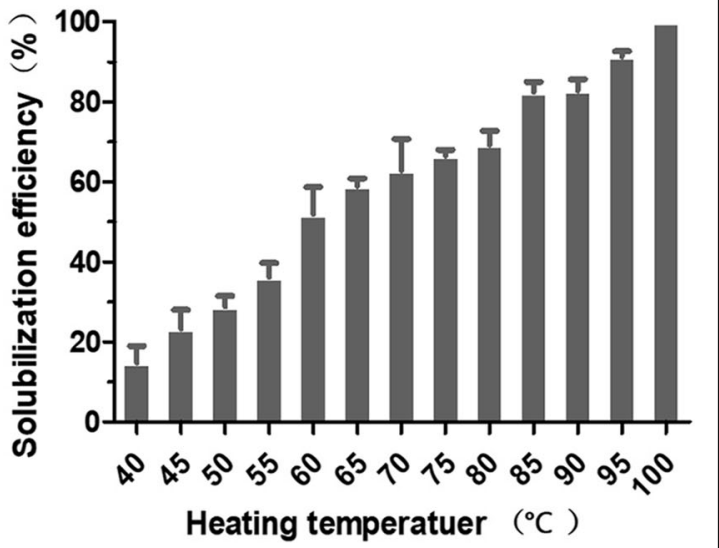

Fig. 3 Effects of heating temperature on the solubilization of NM IBs with one-step heating method. Equal amount of purified NM IBs was suspended in $1 \mathrm{~mL} 10 \mathrm{mmol} / \mathrm{L}$ Tris- $\mathrm{HCl}$ at pH 8.0 containing $4 \mathrm{mmol} / \mathrm{L}$ urea and heating at different temperatures $\left(40-100^{\circ} \mathrm{C}\right)$. a SDS-PAGE analysis of the effect of heating temperature. $\mathbf{b}$ The quantification of solubilization efficiency at different heating temperature

technique problems or the peptides their own properties, the peptides detected by mass spectrometry could not cover $100 \%$ of the full-length sequence; however, both oxidation and carbamylation were already observed (Supplementary Table 1). The cyanate group was detected on the sidechains of both Arg and Lys residues (Fig. 7, Supplementary Table 1). Although there is no evidence in this study to support the $\mathrm{N}$ terminal carbamylation of the recombinant NM solubilized with this heating protocol, still we cannot exclude this possibility. For the downstream experiments that are sensitive to carbamylation, the experiments should be designed carefully.

\section{Discussion}

In current study, we introduce a one-step heating method, which enables efficient recovery of recombinant proteins, in particular spidroins with excellent purify from IBs. The recombinant spirdoins produced with this method can spontaneously self-assembled into structured spherical nanoparticles, which is similar to previously reported nanoparticles derived from other silk proteins. Further, the one-step heating method holds great compatibility to work under different biological buffers and pHs.

Over-expression of spidroins often forms IBs when recombinantly produced in E. coli. Normally, high concentration of denaturant such as $8 \mathrm{~mol} / \mathrm{L}$ urea or $6 \mathrm{~mol} /$ $\mathrm{L}$ guanidine or organic solvents, e.g. hexafluoroisopropanol (HFIP) and formic acid, are used for a solubilization purpose. Subsequently, before processing into various formats extensive dialysis is applied to remove excess denaturant, leading to extra dilution and precipitation. To overcome this phenomenon, recently, many mild

\section{A}

B
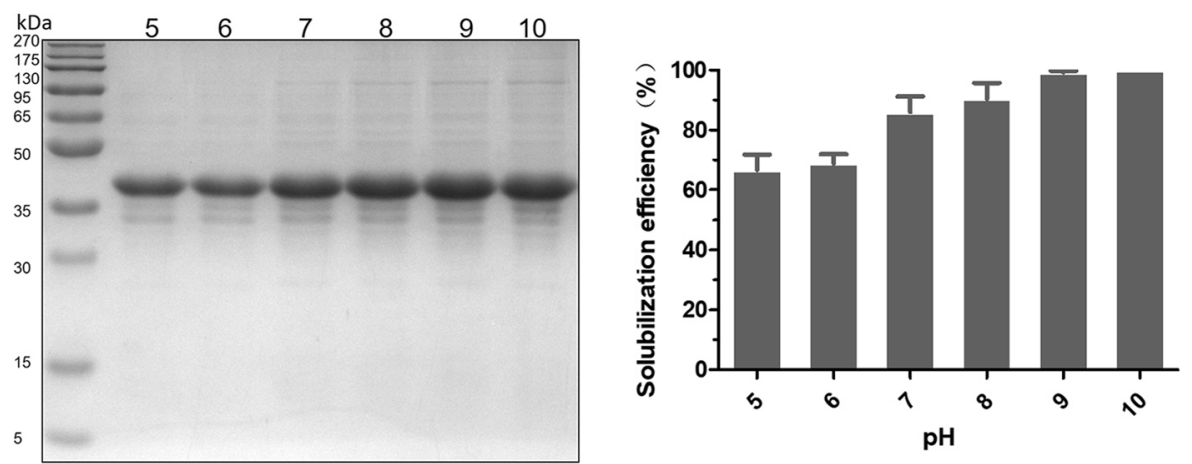

Fig. $4 \mathrm{pH}$ Effects on NM IBs solubilization with one-step heating method. The equal amount of purified NM IBs was suspended in $1 \mathrm{~mL} 10 \mathrm{mmol} /$ $\mathrm{L}$ Tris- $\mathrm{HCl}$ at different $\mathrm{pHs}$ (range from 5.0 to 10.0) in the presence of 4 mol/L urea. a SDS-PAGE analysis of the effects of pH on NM IBs solubilization. $\mathbf{b}$ The quantification of solubilization efficiency at different pHs 

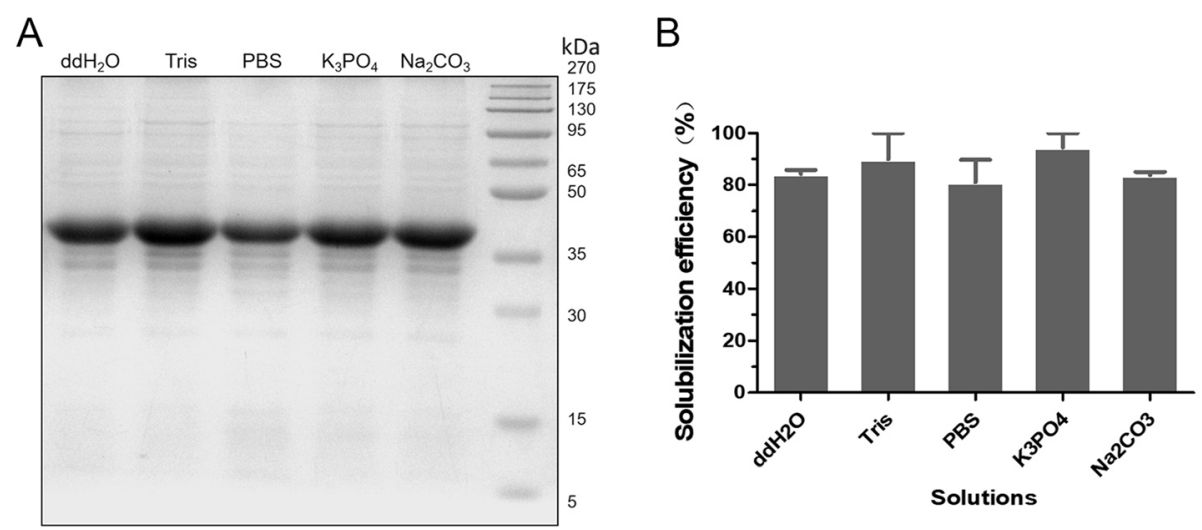

Fig. 5 Effects of different buffers on the solubilization of NM IBs with one-step heating method. Equal amount of purified NM IBs was suspended in $1 \mathrm{~mL}$ different buffers containing $4 \mathrm{~mol} / \mathrm{L}$ urea and solubilized by one-step heating method. a SDS-PAGE analysis of the effect of buffers on the solubility of $\mathrm{NM}$ IBs. ddH2O, deionized water; Tris, $10 \mathrm{mmol} / \mathrm{L}$ Tris- $\mathrm{HCl}$ pH 8.0; PBS, $1 \times \mathrm{PBS} \mathrm{K}_{3} \mathrm{PO}_{4}, 10 \mathrm{mmol} / \mathrm{L}$ potassium phosphate $\mathrm{pH}$ 8.0; $\mathrm{NaCO}$, $10 \mathrm{mmol} / \mathrm{L}$ sodium carbonate $\mathrm{pH}$ 8.0. b The protein solubilization efficiency in different buffers

strategies for solubilizing IBs have been pursued for retaining native-like secondary structures, such as extreme $\mathrm{pH}$, using detergents and freezing-thawing cycle $[31,33,34]$. Tag-free bioengineered spidroins were successfully prepared by thermal extraction and acidic extraction [27]; however, both methods are designed for soluble recombinant spidroins, while for spidroins in insoluble fraction high concentration denaturants are still necessary, which will break native-like secondary structures. Here, one-step heating method is a relatively mild solubilization strategy for dissolving engineered spidroins from IBs, with combining spidroins' high thermal stability and the chaotropic properties of urea. With this method, the purity of solubilized NM from IBs was more than $95 \%$ without additional purification steps. The solubilization efficiency of $\mathrm{NM}$ IBs in Tris- $\mathrm{HCl} \mathrm{pH} 8.0$ containing $4 \mathrm{~mol} / \mathrm{L}$ urea with this method was already comparable to that of $7 \mathrm{~mol} / \mathrm{L}$ urea through traditional urea-denatured method. Even with $2 \mathrm{~mol} / \mathrm{L}$ urea the solubilization efficiency of NM IBs was achieved $50 \%$ by one-step heating method, whereas there were only trace amounts of soluble protein obtained by traditional ureadenatured method (less than 5\%) (Fig. 2). These results indicate that significantly less urea is required within one-step heating method, which confers great probability to maintain the secondary structures probably important for the downstream applications.

In terms of broad buffer and pHs conditions regarding various recombinant protein productions, the one-step heating method shows great feasibility. In current study,
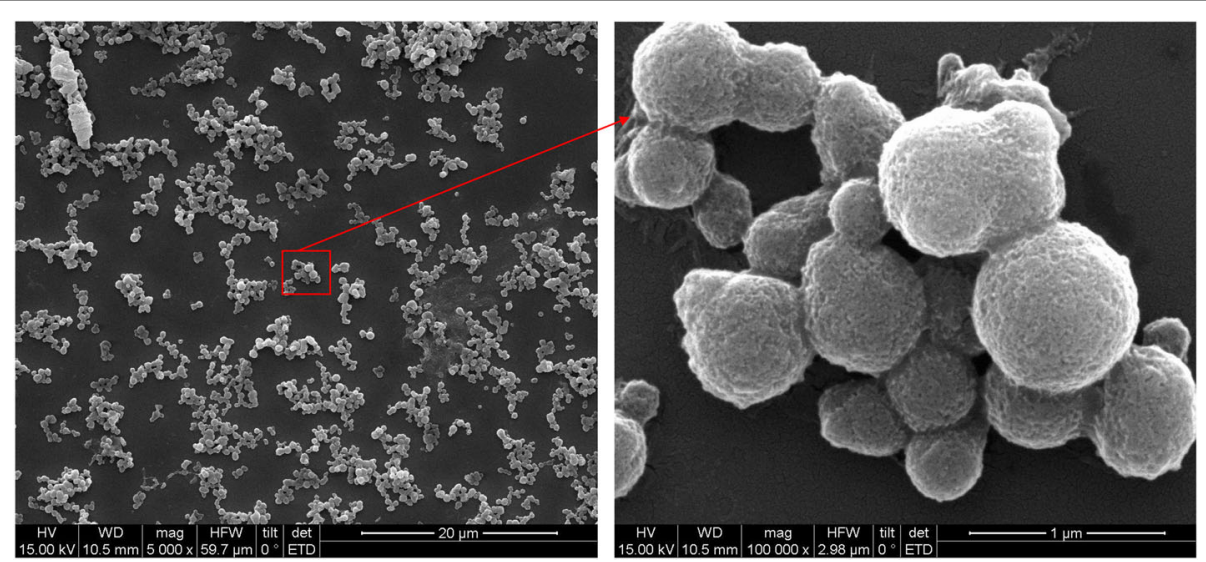

Fig. 6 Characterization of NM nanoparticles. The NM nanoparticles formation was processed through salting out with potassium phosphate. The NM nanoparticles were completely washed with pure water and air-dried on a gold-coated silicon, and subsequently observed under Hitachi scanning electron microscope (Japan, S-4700) with HV as $15 \mathrm{kV}$. The nanoparticles were magnified 5000× (a) and 10,0000x (b) One hundred microliters NM solution $(2.5 \mathrm{mg} / \mathrm{mL}$ ) was mixed with $1 \mathrm{~mL} 2 \mathrm{M}$ potassium phosphate buffer at a $\mathrm{pH}$ of 8.0 and was incubated at room temperature for $2 \mathrm{~h}$. 
MSQPIWTNPNAAMTMTNNLVQCASRSGVLTADQMDDMGM MADSVNSQMQKMGPNPPQH四AMNTAMAAEVAEVVATS PPQSYSAVLNTIGACLRESMMQATGSVDNAFTNEVMQLV KMLSADSANEVSTASASGASYATSTSSAVSSSQATGYST AAGYGNDDDDKHMGEGAGAAAAAGAGAGGAGGYGGGAGS GAGAVARAGAGGAGGYGSGIGGGYGSGAGAAAGAGAGGA GANGGGYGTGAGAGARGADSAGAAAGYGGGVGTGTGSSA GYGRGAGAGAGAGAAAGSGAGAAGGYGGGYGAGAGAGAG AGGAGAGAGGAGGYAQGYGAGAGAGAGAGTGAGGAGGYG QGYGAGSGAGAGGAGGYGAGAGAGAGAGGASGYGQGYGD GAGAGAGAAAAAGAAAGARGAGGYGGGAGDGAGAGAGAU $\mathrm{E}$

Fig. 7 Carbamylation analysis of NM purified with the one-step heating protocol. The NM purified with the one-step heating protocol was trypsinated and analyzed by mass spectrometry. The peptide fragments observed by mass spectrometry were shown in red. The arginine and lysine that are carbamylated were boxed

the solubilization efficiency of NM IBs was not very sensitive to normal buffer conditions, yet the different $\mathrm{pHs}$ and heating temperatures showed effects (Figs. 4 and 5). Although higher temperature promotes IBs solubilization, we do not exclude the possibility that the efficiency at relatively low temperature could be compensated by increasing incubation time. One-step heating method prefers neutral and alkaline conditions, however, under acidic condition it is still working but with slightly lower efficiency.

Despite the popularity as an effective protein denaturant, using urea increases the risk of carbamylation, in which the primary amino groups will be carbamylated [35]. The extent of carbamylation depends on the temperature, $\mathrm{pH}$, and incubation time [36]. There are several ways to minimize protein/peptide carbamylation, e.g. always using freshly prepared urea solution from the highest-quality powder, avoiding long time heating, and selecting suitable buffers (like Tris- $\mathrm{HCl}$, or ammonium containing buffers) [37]. In our protocol, the heating process is a prerequisite, but still to lower the risk getting carbamylated we recommend to use fresh urea with highest quality, Tris- $\mathrm{HCl}$ or or ammonium containing buffers, and shorten the incubation time. If the downstream application or testing is very sensitive to carbamylation, then this protocol should be optimized and applied carefully, otherwise other protocols should be pursued. Generally, we recommend the following conditions: heating temperature $70-90^{\circ} \mathrm{C}$ for $20 \mathrm{~min}, \mathrm{pH} 7.0-8.5$, urea concentration $2-4 \mathrm{~mol} / \mathrm{L}$, and working buffer $10 \mathrm{mmol} / \mathrm{L}$ Tris- $\mathrm{HCl}$ or other ammonium containing buffers.

\section{Conclusions}

The one-step heating method for solubilizing NM IBs is much more efficient and milder than the traditional urea-denatured method though urea-induced modifications may occur. Solubilization of NM IBs with low concentration of urea affords a good possibility for downstream nanoparticle or fibers formation. This method is not only suitable for recombinant spidroin preparation, but also holds the great potential for solubilizing other recombinant IBs forming proteins. If the downstream application of solubilized protein is sensitive to carbamylation, then this protocol should be applied carefully, due to the potential modification of carbamylation of amino groups in the existence of urea.

\section{Methods}

\section{Expression and purification of NM IBs from E. coli}

A gene fragment encoding a 430 -aa protein (NM) that corresponds to the 261-aa repetitive sequence and the 161-aa NT domain of A.ventricosus MiSp was synthesized, and an enterokinase cleavage site (DDDDK) was introduced between the NT domain and the repetitive sequence (Fig. 1a). The gene fragment was inserted into pET-32a plasmid within NdeI and XhoI restriction sites (Fig. 1b) and confirmed by sequencing. The plasmid with correct sequence was transformed into E. coli BL21 (DE3) competent cells. For protein expression, the E. coli cells were grown at $37^{\circ} \mathrm{C}$ in $\mathrm{LB}$ medium containing $30 \mu \mathrm{g} / \mathrm{mL}$ ampicillin until $\mathrm{OD}_{600}$ is around 1.0, and 1 $\mathrm{mmol} / \mathrm{L}$ IPTG (final concentration) was added. The expression lasted for $4 \mathrm{~h}$ at $37^{\circ} \mathrm{C}$. The cells then were harvested by centrifugation and lysed by sonication for 30 min on ice. In order to obtain pure NM IBs, the insoluble pellets were washed as previously described [33].

\section{Solubilization of NM IBs}

Equal amount of purified NM IBs was resuspended in Tris buffer at $\mathrm{pH} 8.0$ containing different molar concentrations of urea $(0-7 \mathrm{~mol} / \mathrm{L})$. For the traditional ureadenatured method, the suspension was stirred for $1 \mathrm{~h}$ at room temperature and centrifuged $(12,000 \times \mathrm{g}, 30 \mathrm{~min}$, $4{ }^{\circ} \mathrm{C}$ ) to collect the supernatant. For the one-step heating method, the suspension was heated at $85^{\circ} \mathrm{C}$ for $20 \mathrm{~min}$ and centrifuged at $12,000 \times \mathrm{g}$ for $30 \mathrm{~min}$ at $4{ }^{\circ} \mathrm{C}$ for collecting the supernatant. Supernatants were analyzed by SDS-PAGE. The soluble protein was quantified using Micro BCA Protein Assay Kit (Thermo, US). The solubilization efficiency from IBs was evaluated by the ratio of soluble protein concentration to that from 7 $\mathrm{mol} / \mathrm{L}$ urea mediated one-step heating method.

\section{Solubilization of NM IBs in Tris buffer at different pHs and temperature}

Equal amount of pure NM IBs was suspended in $1 \mathrm{~mL}$ $10 \mathrm{mmol} / \mathrm{L}$ Tris- $\mathrm{HCl}$ at different $\mathrm{pHs}$ (range from 5.0 to $10.0)$ in the presence of $4 \mathrm{~mol} / \mathrm{L}$ urea. The homogenous IBs suspensions were heated at $85^{\circ} \mathrm{C}$ for $20 \mathrm{~min}$ and centrifuged at $12,000 \times \mathrm{g}$ for $30 \mathrm{~min}$ at $4{ }^{\circ} \mathrm{C}$ for supernatant collections. On the other hand, homogenous 
suspensions of NM IBs were suspended in $10 \mathrm{mmol} / \mathrm{L}$ Tris- $\mathrm{HCl}$ at $\mathrm{pH} 8.0$ containing $4 \mathrm{~mol} / \mathrm{L}$ urea. The suspensions were heated at different temperatures $\left(40-100^{\circ} \mathrm{C}\right)$ for $20 \mathrm{~min}$ and centrifuged. Supernatants were analyzed by SDS-PAGE and protein concentrations were quantified using Micro BCA Protein Assay Kit. The protein solubilization efficiency was evaluated by the ratio of soluble protein to total protein.

\section{Solubility of NM IBs in different buffers}

Five different biological buffers in presence of $4 \mathrm{~mol} / \mathrm{L}$ urea were employed to solubilize NM IBs: $1 \times$ PBS, 10 $\mathrm{mmol} / \mathrm{L}$ sodium carbonate $\left(\mathrm{NaCO}_{3}, \mathrm{pH} 8.0\right), 10 \mathrm{mmol} / \mathrm{L}$ potassium phosphate $\left(\mathrm{K}_{3} \mathrm{PO}_{4}, \mathrm{pH} 8.0\right), 10 \mathrm{mmol} / \mathrm{L}$ Tris$\mathrm{HCl}(\mathrm{pH} \mathrm{8.0)}$, and deionized water (ddH2O). Equal amount of purified NM IBs was suspended in $1 \mathrm{~mL}$ different buffers and mixed thoroughly to get homogenous suspensions. The IBs suspensions were heated at $85^{\circ} \mathrm{C}$ for $20 \mathrm{~min}$ and centrifuged at $12,000 \mathrm{~g}$ for $30 \mathrm{~min}$ at $4{ }^{\circ} \mathrm{C}$ for clear supernatants collection, respectively. Supernatants were analyzed parallelly by SDS-PAGE and the protein solubilization efficiency was evaluated as above.

\section{Preparation of NM nanoparticles}

The recombinant NM from IBs prepared with one-step heating method was dialyzed in $10 \mathrm{mmol} / \mathrm{L}$ Tris- $\mathrm{HCl}$ at $\mathrm{pH}$ 8.0. One hundred microliters NM solution $(2.5 \mathrm{mg} / \mathrm{mL})$ was mixed with $1 \mathrm{~mL} 2 \mathrm{~mol} / \mathrm{L}$ potassium phosphate buffer at a $\mathrm{pH}$ of 8.0. The solution was incubated at room temperature for $2 \mathrm{~h}$ and then dialyzed overnight against ultrapure water. For scanning electron microscopy (SEM), NM nanoparticles were completely washed with pure water and air-dried on a gold-coated silicon. The particles were observed under a Hitachi scanning electron microscope (Japan, S-4700).

\section{Mass spectrometry analysis}

NM protein solubilized from IBs generated by one-step heating method was analyzed with nano-LC mass spectrometry on an EASY-nLC II (Thermo Fisher Scientific). The sample was digested with trypsin (Promega) at $37^{\circ} \mathrm{C}$ for $20 \mathrm{~h}$. The digested mix was lyophilized and resuspended in 0.1\% FA. For each full scan Map (MS2 scan), twenty fragments were collected. The raw data were processed using Mascot 2.2 program, and potential modifications, e.g. carbamylation and oxidation were analyzed.

\section{Supplementary information}

Supplementary information accompanies this paper at https://doi.org/10. 1186/s12896-020-00630-1.

Additional file 1.

\section{Abbreviations}

NM IBs: NM inclusion bodies; MaSp: Major ampullate spidroin; MiSp: Minor ampullate spidroin; E. coli: Escherichia coli; A. ventricosus: Araneus ventricosus;
NT: N-terminal domain; CT: C-terminal domain; SEM: Scanning electron microscopy

\section{Acknowledgements \\ Not applicable}

\section{Authors' contributions}

H.C., H.Y. and Y.T. performed the experiments. G.C. designed the MiSp DNA sequence. G.C. and X.Q. analyzed the data and wrote the paper. X.Q. and S.X. conceived and supervised the study. All authors discussed the results and commented on the manuscript. The author(s) read and approved the final manuscript.

\section{Funding}

This work was financially supported by National Nature Science Foundation of China (No. 31771003, No. 31400789), Jiangsu Provincial Innovative Team, Priority Academic Program Development of Jiangsu Higher Education Institutions (PAPD). The funders had no role in study design, data collection, interpretation, or decision-making in relation to submission for publication.

\section{Availability of data and materials}

All data generated or analyzed during this study are included in this published article.

Ethics approval and consent to participate

Not applicable.

\section{Consent for publication}

Not applicable.

\section{Competing interests}

The authors declare that they have no competing interests.

\section{Author details}

${ }^{1}$ The Jiangsu Key Laboratory of Infection and Immunity, Institutes of Biology and Medical Sciences, Soochow University, Suzhou 215123, Jiangsu, China. ${ }^{2}$ Department of Neurobiology, Care Sciences and Society, Center for Alzheimer Research, Division of Neurogeriatrics, Karolinska Institutet, 14157 Huddinge, Sweden.

Received: 12 March 2020 Accepted: 2 July 2020

Published online: 10 July 2020

References

1. Zhang L, Xiang Z, Zhao G, Wu Z. Cui H: [functionalized genetic engineered silk-based biomaterials and their applications]. Sheng Wu Gong Cheng Xue Bao. 2019;35:956-71.

2. Saric M, Scheibel T. Engineering of silk proteins for materials applications. Curr Opin Biotechnol. 2019;60:213-20

3. Nguyen TP, Nguyen QV, Nguyen VH, Le TH, Huynh VQN, Vo DN, Trinh QT, Kim SY, Le QV. Silk fibroin-based biomaterials for biomedical applications: a review. Polymers (Basel). 2019;11:1933.

4. Aigner TB, DeSimone E, Scheibel T. Biomedical applications of recombinant silk-based materials. Adv Mater. 2018;30:e1704636.

5. Yoshida M, Kamei N, Muto K, Kunisawa J, Takayama K, Peppas NA, TakedaMorishita M. Complexation hydrogels as potential carriers in oral vaccine delivery systems. Eur J Pharm Biopharm. 2017;112:138-42.

6. Hofer M, Winter G, Myschik J. Recombinant spider silk particles for controlled delivery of protein drugs. Biomaterials. 2012;33:1554-62.

7. Lammel A, Schwab M, Hofer M, Winter G, Scheibel T. Recombinant spider silk particles as drug delivery vehicles. Biomaterials. 2011;32:2233-40.

8. Lucke M, Mottas I, Herbst T, Hotz C, Romer L, Schierling M, Herold HM, Slotta U, Spinetti T, Scheibel T, et al. Engineered hybrid spider silk particles as delivery system for peptide vaccines. Biomaterials. 2018;172:105-15.

9. Schierling MB, Doblhofer E, Scheibel T. Cellular uptake of drug loaded spider silk particles. Biomater Sci. 2016:4:1515-23.

10. Tokareva O, Michalczechen-Lacerda VA, Rech EL, Kaplan DL. Recombinant DNA production of spider silk proteins. Microb Biotechnol. 2013;6:651-63.

11. Rising A, Widhe M, Johansson J, Hedhammar M. Spider silk proteins: recent advances in recombinant production, structure-function relationships and biomedical applications. Cell Mol Life Sci. 2011;68:169-84. 
12. Scheibel T. Spider silks: recombinant synthesis, assembly, spinning, and engineering of synthetic proteins. Microb Cell Factories. 2004;3:14.

13. Bowen CH, Reed TJ, Sargent CJ, Mpamo B, Galazka JM, Zhang F. Seeded chain-growth polymerization of proteins in living bacterial cells. ACS Synth Biol. 2019;8:2651-8.

14. Radtke C. Natural occurring silks and their analogues as materials for nerve conduits. Int J Mol Sci. 2016;17:1754.

15. Chen G, Liu X, Zhang Y, Lin S, Yang Z, Johansson J, Rising A, Meng Q. Fulllength minor ampullate spidroin gene sequence. PLoS One. 2012;7:e52293.

16. Guinea GV, Elices M, Plaza GR, Perea GB, Daza R, Riekel C, Agullo-Rueda F, Hayashi C, Zhao Y, Perez-Rigueiro J. Minor ampullate silks from Nephila and Argiope spiders: tensile properties and microstructural characterization. Biomacromolecules. 2012;13:2087-98.

17. Rising A, Hjalm G, Engstrom W, Johansson J. N-terminal nonrepetitive domain common to dragline, flagelliform, and cylindriform spider silk proteins. Biomacromolecules. 2006;7:3120-4.

18. Hagn F, Eisoldt L, Hardy JG, Vendrely C, Coles M, Scheibel T, Kessler H. A conserved spider silk domain acts as a molecular switch that controls fibre assembly. Nature. 2010;465:239-42.

19. Zhang H, Zhou F, Jiang X, Cao M, Wang S, Zou H, Cao Y, Xian M, Liu H. Microbial production of amino acid-modified spider dragline silk protein with intensively improved mechanical properties. Prep Biochem Biotechnol. 2016;46:552-8.

20. Liu T, Liang A, Liang Z, Li G, Wang F. Construction of a synthetic Araneus ventricosus dragline silk gene multimer and its expression in Escherichia coli. 3 Biotech. 2018:8:252.

21. Fahnestock SR, Yao Z, Bedzyk LA. Microbial production of spider silk proteins. J Biotechnol. 2000;74:105-19.

22. Widhe M, Johansson J, Hedhammar M, Rising A. Invited review current progress and limitations of spider silk for biomedical applications. Biopolymers. 2012;97:468-78.

23. Werten MW, Moers AP, Vong $\mathrm{T}$, Zuilhof $\mathrm{H}$, van Hest JC, de Wolf FA. Biosynthesis of an amphiphilic silk-like polymer. Biomacromolecules. 2008;9: 1705-11.

24. Werten MWT, Eggink G, Cohen Stuart MA, de Wolf FA. Production of protein-based polymers in Pichia pastoris. Biotechnol Adv. 2019;37:642-66.

25. Edlund AM, Jones J, Lewis R, Quinn JC. Economic feasibility and environmental impact of synthetic spider silk production from escherichia coli. New Biotechnol. 2018;42:12-8.

26. Bini E, Foo CW, Huang J, Karageorgiou V, Kitchel B, Kaplan DL. RGDfunctionalized bioengineered spider dragline silk biomaterial. Biomacromolecules. 2006;7:3139-45.

27. Dams-Kozlowska H, Majer A, Tomasiewicz P, Lozinska J, Kaplan DL, Mackiewicz A. Purification and cytotoxicity of tag-free bioengineered spider silk proteins. J Biomed Mater Res A. 2013;101:456-64.

28. Jastrzebska K, Felcyn E, Kozak M, Szybowicz M, Buchwald T, Pietralik Z, Jesionowski T, Mackiewicz A, Dams-Kozlowska H. The method of purifying bioengineered spider silk determines the silk sphere properties. Sci Rep. 2016;6:28106.

29. Mello CM, Soares JW, Arcidiacono S, Butler MM. Acid extraction and purification of recombinant spider silk proteins. Biomacromolecules. 2004;5:1849-52.

30. Fahnestock SR, Bedzyk LA. Production of synthetic spider dragline silk protein in Pichia pastoris. Appl Microbiol Biotechnol. 1997;47:33-9.

31. Singh A, Upadhyay V, Upadhyay AK, Singh SM, Panda AK. Protein recovery from inclusion bodies of Escherichia coli using mild solubilization process. Microb Cell Factories. 2015;14:41.

32. Ryan BJ, Kinsella GK. Differential precipitation and Solubilization of proteins. Methods Mol Biol. 2017;1485:191-208.

33. Qi X, Sun Y, Xiong S. A single freeze-thawing cycle for highly efficient solubilization of inclusion body proteins and its refolding into bioactive form. Microb Cell Factories. 2015;14:24.

34. Singhvi P, Saneja A, Srichandan S, Panda AK. Bacterial inclusion bodies: a treasure trove of bioactive proteins. Trends Biotechnol. 2020;38:474-86.

35. Delanghe S, Delanghe JR, Speeckaert R, Van Biesen W, Speeckaert MM. Mechanisms and consequences of carbamoylation. Nat Rev Nephrol. 2017;13:580-93.

36. Kollipara L, Zahedi RP. Protein carbamylation: in vivo modification or in vitro artefact? Proteomics. 2013;13:941-4.

37. Sun S, Zhou JY, Yang W, Zhang H. Inhibition of protein carbamylation in urea solution using ammonium-containing buffers. Anal Biochem. 2014;446:76-81.

\section{Publisher's Note}

Springer Nature remains neutral with regard to jurisdictional claims in published maps and institutional affiliations.

\section{Ready to submit your research? Choose BMC and benefit from:}

- fast, convenient online submission

- thorough peer review by experienced researchers in your field

- rapid publication on acceptance

- support for research data, including large and complex data types

- gold Open Access which fosters wider collaboration and increased citations

- maximum visibility for your research: over $100 \mathrm{M}$ website views per year

At BMC, research is always in progress.

Learn more biomedcentral.com/submissions 